\title{
Increased IL-17RA and IL-17RC in End-Stage COPD and the Contribution to Mast Cell Secretion of FGF-2 and VEGF
}

\author{
Abraham B. Roos ${ }^{1,2,3^{*}}$, Michiko Mori ${ }^{1}$, Harpreet K. Gura ${ }^{4,5}$, Axel Lorentz ${ }^{6}$, Leif Bjermer ${ }^{7}$, Hans Jürgen Hoffmann ${ }^{4,5}$, \\ Jonas S. Erjefält ${ }^{1}$ and Martin R. Stampfli, ${ }^{2,8}$
}

\begin{abstract}
Mast cells are accumulated in advanced chronic obstructive pulmonary disease (COPD), and interleukin (IL)-17 signaling plays a role in disease progression. The expression, localization and functional relevance of IL-17 receptor (R)A and IL-17RC was explored in COPD by immunodetection, and functional assays.

IL-17RA and IL-17RC was increased in very severe COPD, and expressed by mast cells. Increased secretion of the pro-angiogenic basic fibroblast growth factor and vascular endothelial growth factor was observed in vitro-maintained mast cells stimulated with IL-17A. Expression of these mediators was confirmed in end-stage COPD. Thus, accumulation of mast cells in COPD may contribute to vascular remodeling.
\end{abstract}

\section{Letter}

The expression of IL-17A is elevated in lung tissue of patients with chronic obstructive pulmonary disease (COPD), and the cytokine is linked to the pathology associated with the disease $[1,2]$. In the current study, we investigated the expression of receptors activated by IL-17A (IL-17 receptor (R)A and IL-17RC), to determine the responisveness to this cytokine in COPD. We used automated immunohistochemistry to detect the expression of IL-17RA (mouse anti-IL17RA, R\&D Systems, Minneapolis, MN, USA) and IL-17RC (mouse anti-IL17RC, Atlas Antibodies, Stockholm, Sweden) in peripheral lung tissue sections obtained from a previously characterized cohort of COPD patients and relevant controls (Table 1) [3]. The local ethics committee in Lund approved the study protocol, and all subjects signed an informed consent form.

IL-17RA immunoreactivity was observed within the cytoplasm of cells located within the small airway submucosa, as well as the alveolar parenchyma in both asymptomatic controls and patients with COPD (Fig. 1a-b). The airway

\footnotetext{
* Correspondence: abraham.roos@astrazeneca.com

${ }^{1}$ Department of Experimental Medical Science, Lund University, Lund, Sweden

${ }^{2}$ Department of Pathology and Molecular Medicine, McMaster Immunology Research Centre, McMaster University, Hamilton, ON, Canada

Full list of author information is available at the end of the article
}

epithelium displayed minimal immunoreactivity. Similarly, while some immunoreactivity to IL-17RC was observed in the airway epithelium, the strongest signal was observed in cells scattered within the airway submucosa and lung parenchyma (Fig. 1c-d). The number of IL-17RA+ and IL-17RC+ cells were increased specifically in very severe (GOLD IV) COPD (Fig. 1e and f), suggesting an involvement of these receptors in COPD progression. Whereas the exact mechanism underlying increased IL-17RA/IL-17RC in advanced COPD still remains unknown, it may involve the pro-inflammatory milieu documented in COPD, which may be escalated in end-stage disease.

As not only structural cells displayed immunoreactivity, co-staining techniques for different cellular markers was next performed to determine the specific cell types expressing IL-17RA and IL-17RC in the peripheral lung. In accordance with previous findings, expression was observed across different immune cell populations, including B lymphocytes (Fig. $1 \mathrm{~h}$ and $\mathrm{m}$ ), as well as on structural cells. Expression of both IL-17RA and IL-17RC was also detected on tryptase + mast cells (mouse anti-tryptase, Merck-Millipore, Solna, Sweden) (Fig. 1k and p). Previous studies have documented an accumulation of mast cells in lung tissue of patients with advanced COPD [3], although the role of mast cells in COPD remains elusive. We thus explored the potential 
Table 1 Baseline demographics and clinical characteristics

\begin{tabular}{|c|c|c|c|c|c|c|}
\hline & Never smokers & Smokers w/o COPD & COPD GOLD I & COPD GOLD II-III & COPD GOLD IV & p ANOVA \\
\hline Subjects (n) & 7 & 6 & 6 & 13 & 10 & \\
\hline Gender (female/male) & $5 / 2$ & $4 / 2$ & $3 / 3$ & $2 / 11$ & $6 / 4$ & \\
\hline Age (years) & $63 \pm 4.8$ & $57 \pm 3.3$ & $67 \pm 2.9$ & $68 \pm 1.9$ & $61 \pm 1.4$ & ns \\
\hline Height (m) & $1.64 \pm 0.1$ & $1.71 \pm 0.1$ & $1.74 \pm 0.1$ & $1.73 \pm 0.1$ & $1.69 \pm 0.1$ & ns \\
\hline Weight (kg) & $65 \pm 4.6$ & $69 \pm 4.6$ & $69 \pm 5.7$ & $73 \pm 3.1$ & $65 \pm 1.7$ & ns \\
\hline Body mass index & $24 \pm 1.3$ & $24 \pm 1.0$ & $23 \pm 1.2$ & $24 \pm 1.1$ & $23 \pm 1.0$ & ns \\
\hline Pack years & N/A & $43 \pm 8.2$ & $40 \pm 7.6$ & $48 \pm 3.3$ & $41 \pm 3.9$ & ns \\
\hline Smoker/ex-smoker & $\mathrm{N} / \mathrm{A}$ & $4 / 2$ & $3 / 3$ & $5 / 8$ & $0 / 10$ & \\
\hline FEV1/FVC & $86 \pm 5.7$ & $79 \pm 2.0$ & $67 \pm 0.9$ & $55 \pm 2.8$ & $32 \pm 2.0$ & $<0.001$ \\
\hline \%FEV1 & $110 \pm 6.2$ & $98 \pm 6.0$ & $87 \pm 2.3$ & $64 \pm 3.1$ & $23 \pm 1.4$ & $<0.001$ \\
\hline Corticosteroids (yes/no/unknown) & $0 / 7 / 0$ & $0 / 6 / 0$ & $0 / 6 / 0$ & $2 / 11 / 0$ & $9 / 0 / 1$ & \\
\hline Bronchodialator (yes/no/unknown) & $0 / 7 / 0$ & $0 / 6 / 0$ & $3 / 3 / 0$ & $3 / 10 / 0$ & $9 / 0 / 1$ & \\
\hline
\end{tabular}

Values are mean \pm standard error of mean

COPD chronic obstructive pulmonary disease, $F E V_{1}$ forced expiratory volume in $1 \mathrm{~s}$, (F)VC (forced) vital capacity, GOLD Global Initiative for Chronic Obstructive Lung Disease

functional relevance of IL-17 receptor expression on mast cells in COPD. To this end, CD133 ${ }^{+}$hematopoietic stem cell progenitors were isolated $(n=5)$ and differentiated into mast cells, in vitro, as described elsewhere [4]. $10^{5}$ mast cells were following 4 weeks maturation stimulated for 8 hours with $1000 \mathrm{ng}$ IL-17A (R\&D Systems, Minneapolis, MN, USA), or left unstimulated. Lipopolysaccharide (LPS, Sigma-Aldrich) was used as a positive control.

The in vitro-matured cells exhibited surface markers and functionality consistent with in vivo mast cells (i.e. expression of tryptase, chymase, c-kit and FceR1; data not shown) $[4,5]$. In addition, mRNA transcripts of both IL17RA and IL17RC were detected following in vitromaturation (data not shown), supporting a phenotypic resemblance to pulmonary mast cells. To evaluate the potential contribution of IL-17A responsive mast cells to the pathology of COPD, we assessed the secretion of proteins associated with COPD by multiplex laser bead technology (41/11-plex Human Cytokine/Chemokine Arrays, Eve Technologies, Calgary, Canada). In line with previous documented ability of mast cells to produce pro-angiogenic factors [6, 7], IL-17A stimulated the secretion of fibroblast growth factor (FGF)-2 and vascular endothelial growth factor (VEGF) (Fig. 1q and r). Although the increases were relativiely small (2-fold increase for FGF-2 and 1.5-fold increase for VEGF), these observations demonstrate the potential role for mast cells in vascular remodeling in COPD. We used a relatively high concentration of IL-17A to activate mast cells. While the biological relevance of this concentration may be debated, the levels of IL-17A may be enriched in the pulmonary microenviroment. Furthermore, a ten fold lower dose was able to induce the secretion of FGF-2 in a pilot study (data not shown). Future studies investigating pulmonary mast cells isolated from COPD patients could provide imporant clues to the biological relevance of these initial findings.

The inflammatory mediator profile was, in contrast, unaffected by stimulation by IL-17A. The lack of proinflammatory responisveness of mast cells to IL-17A may be explained by earler reports of enhanced effects by other cytokines, such as TNF $\alpha$, IL- $1 \beta$ and IL-22 [8]. Thus, future studies investigating the potential inflammatory response of mast cells in response to IL-17A would benefit from including co-stimulation, or possibly the inflammatory milieu associated with COPD.

We next investigated the immunoreactivity for FGF-2 and VEGF in lung tissue specimens from end-stage COPD patients, to confirm expression by mast cells. In support of the in vitro data establishing a potential role for mast cells in the regulation of vascular growth factors in COPD, pulmonary mast cells were positive for both FGF-2 and VEGF (Fig. 1i and j). The biological relevance of this observation needs to be examined further, in particular as structural cells exhibit marked staining intensity in pulmonary tissue.

Both increased number of pulmonary vessels and vascular area is observed in COPD [9]. Moreover, medial thickness of pulmonary vessels exhibit an inverse relation to lung function, suggesting increased vascular remodeling in advanced disease. Others have demonstrated that extra-pulmonary mast cells participate in vascular remodeling by the production of proangiogenic factors such as FGF-2 and VEGF $[6,7]$. In addition, it was recently demonstrated that IL-17A directly induces the production of VEGF and FGF-2 by the endothelium [10]. 


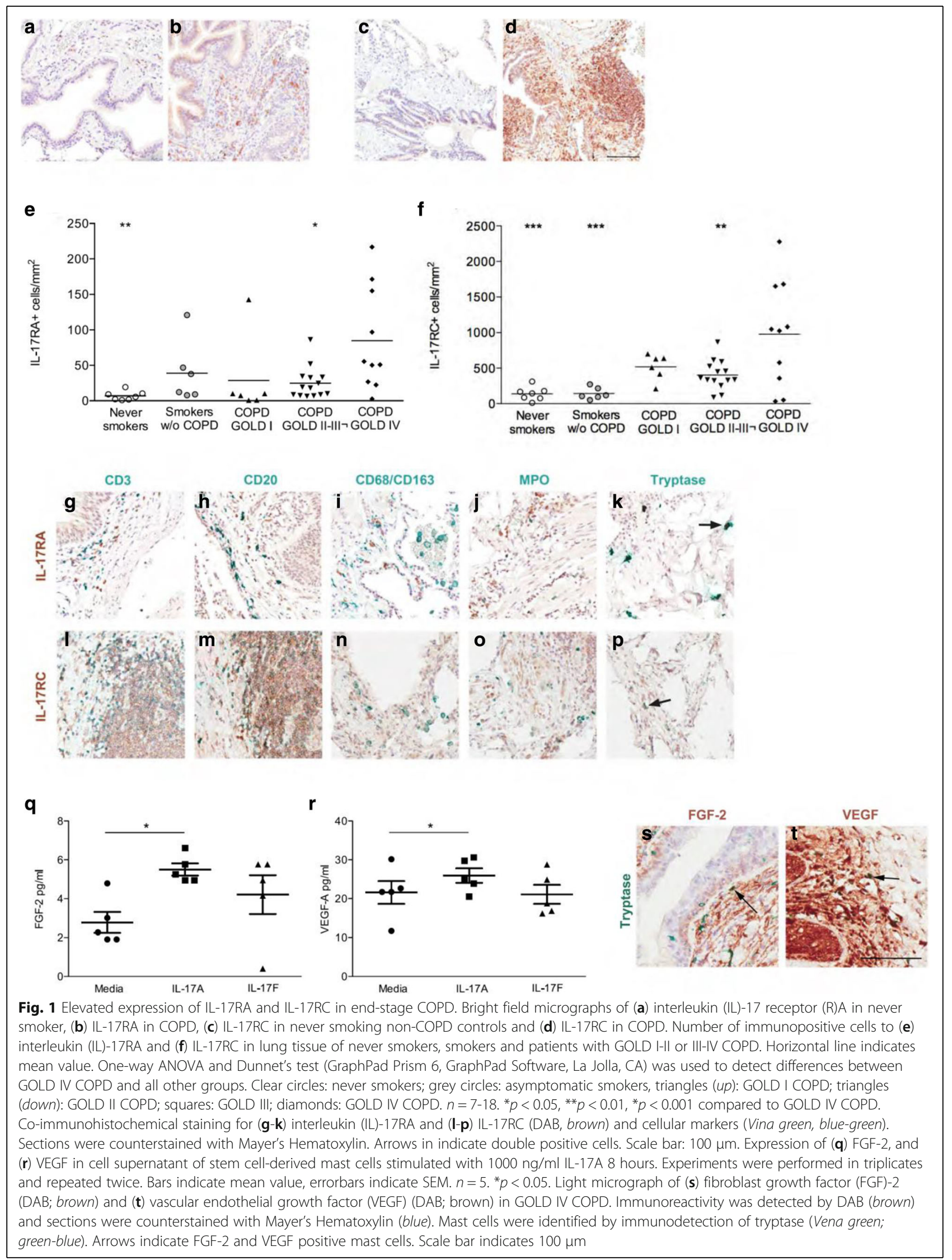


The current data support increased IL-17 signaling in end-stage COPD, and stimulation of mast cell-derived vascular growth factors by IL-17A. Together, these findings designate a potential function for mast cells in advanced COPD, and warrant additional studies with the ultimate objective to target mast cells to reduce the morbidity associated with COPD.

\section{Acknowledgements}

The authors would like to thank Joanna Kasinska, Marie Bailey (McMaster University, Hamilton, Canada), Britt-Marie G Nilsson, Karin Jansner (Lund University, Lund, Sweden), Ellen Margrete Raaby and Beatriz Seville-Jensen (Aarhus University, Denmark) for excellent technical support.

\section{Funding}

Canadian Institutes of Health Research (MOP-64390 and MOP-87517), the Swedish Heart-lung Foundation, the Swedish Research Council, the Swedish Society for Medical Research. The funding sources had no influence on study design, sample collection, data analysis and interpretation, or preparation of this manuscript.

\section{Availability of data and materials}

The datasets generated during and/or analysed during the current study are available from the corresponding author on reasonable request.

\section{Authors' contributions}

Conception and design: ABR, MM, HKG, LB, AL, JSE, HJH and MRS. Acquisition of data: $A B R, M M, H K G, L B$. Analysis and interpretation: $A B R, M M, H K G, A L, L B$, JSE, HJH and MRS. Drafting the manuscript for important intellectual content: $A B R, M M, H K G, L B, A L, J S E, H J H$ and MRS. All authors approved the final version to be published.

\section{Competing interests}

ABR is employed by AstraZeneca. There are no other competing interest with regard to this manuscript to declare.

\section{Consent for publication}

Not applicable.

\section{Ethics approval and consent to participate}

Informed consent was obtained from all subjects within the study. The local research ethics board in Lund, Sweden approved the study protocol and written consent form.

\section{Financial Support}

Canadian Institutes of Health Research (MOP-64390 and MOP-87517), the Swedish Heart-lung Foundation, the Swedish Research Council, the Swedish Society for Medical Research.

\section{Publisher's Note}

Springer Nature remains neutral with regard to jurisdictional claims in published maps and institutional affiliations.

\footnotetext{
Author details

'Department of Experimental Medical Science, Lund University, Lund, Sweden. ${ }^{2}$ Department of Pathology and Molecular Medicine, McMaster Immunology Research Centre, McMaster University, Hamilton, ON, Canada. ${ }^{3}$ AstraZeneca R\&D Gothenburg, Respiratory, Inflammation and Autoimmunity, Innovative Medicines, Pepparedsleden 1, 43183 Mölndal, Sweden. ${ }^{4}$ Department of Respiratory Diseases and Allergy, Aarhus University Hospital, Aarhus, Denmark. ${ }^{5}$ Department of Clinical Medicine, Aarhus University, Aarhus, Denmark. ${ }^{6}$ Department of Nutritional Medicine, University of Hohenheim, Stuttgart, Germany. ${ }^{7}$ Department of Respiratory Medicine and Allergology, Lund University, Lund, Sweden. ${ }^{8}$ Department of Medicine, Firestone Institute of Respiratory Health at St. Joseph's Health Care, Hamilton, ON, Canada.
}

Received: 10 February 2017 Accepted: 2 March 2017

Published online: 15 March 2017

\section{References}

1. Roos AB, Sanden C, Mori M, Bjermer L, Stampfli MR, Erjefalt JS: IL-17A Is Elevated in End-Stage Chronic Obstructive Pulmonary Disease and Contributes to Cigarette Smoke-induced Lymphoid Neogenesis. Am J Respir Crit Care Med. 2015;191(11):1232-41.

2. Roos $A B$, Sethi $S$, Nikota J, Wrona $C T$, Dorrington MG, Sanden $C$, Bauer $C M$, Shen P, Bowdish D, Stevenson CS, et al. IL-17A and the Promotion of Neutrophilia in Acute Exacerbation of Chronic Obstructive Pulmonary Disease. Am J Respir Crit Care Med. 2015;192(4):428-37.

3. Andersson CK, Mori M, Bjermer L, Lofdahl CG, Erjefalt JS: Alterations in lung mast cell populations in patients with chronic obstructive pulmonary disease. Am J Respir Crit Care Med. 2010:181(3):206-17.

4. Andersen HB, Holm M, Hetland TE, Dahl C, Junker S, Schiøtz PO, Hoffmann $\mathrm{HJ}$. Comparison of short term in vitro cultured human mast cells from different progenitors - Peripheral blood-derived progenitors generate highly mature and functional mast cells. Journal of Immunological Methods. 2008;336(2):166-74.

5. Hoffmann HJ, Frandsen PM, Christensen LH, Schiotz PO, Dahl R. Cultured human mast cells are heterogeneous for expression of the high-affinity lgE receptor FcepsilonRI. Int Arch Allergy Immunol. 2012;157(3):246-50.

6. Zanini A, Chetta A, Saetta M, Baraldo S, D'Ippolito R, Castagnaro A, Neri M, Olivieri D. Chymase-positive mast cells play a role in the vascular component of airway remodeling in asthma. Journal of Allergy and Clinical Immunology. 2007;120(2):329-33.

7. Norrby K. Mast cells and angiogenesis. APMIS. 2002;110(5):355-71.

8. Onishi RM, Gaffen SL. Interleukin-17 and its target genes: mechanisms of interleukin-17 function in disease. Immunology. 2010;129(3):311-21.

9. Zanini A, Chetta A, Saetta M, Baraldo S, Castagnetti C, Nicolini G, Neri M, Olivieri D. Bronchial vascular remodelling in patients with COPD and its relationship with inhaled steroid treatment. Thorax. 2009;64(12):1019-24.

10. Takahashi H, Numasaki M, Lotze MT, Sasaki H. Interleukin-17 enhances bFGF, HGF- and VEGF-induced growth of vascular endothelial cells. Immunology letters. 2005;98(2):189-93.
Submit your next manuscript to BioMed Central and we will help you at every step:

- We accept pre-submission inquiries

- Our selector tool helps you to find the most relevant journal

- We provide round the clock customer support

- Convenient online submission

- Thorough peer review

- Inclusion in PubMed and all major indexing services

- Maximum visibility for your research

Submit your manuscript at www.biomedcentral.com/submit
C Biomed Central 